\title{
EDUCAÇÃO LIBERTADORA E (RE)CONHECIMENTO DO NEGRO: A VOZ E A VEZ DAS LITERATURAS AFRICANAS DE LÍNGUA PORTUGUESA NAS SALAS DE AULA
}

\author{
EDUCATION FOR FREEDOM AND KNOULEDGE AND \\ ACKNOULEDGMENT OF THE BLACK PEOPLE: GIVING \\ THE VOICE AND CHANCE TO AFRICAN LITERATURES \\ IN THE PORTUGUESE LANGUAGE IN THE CLASSROOM
}

\author{
Mariana Sousa Dias* \\ Renata Flávia da Silva*
}

Resumo: Este artigo tem por objetivo discutir o estudo das Literaturas Africanas em Língua Portuguesa como importante expressão da educação libertadora, enfatizando a reflexão acerca do sujeito afrodescendente brasileiro. Buscaremos verificar até que ponto esse referencial, como recurso pedagógico, contribui para que o alunado da educação básica possa não apenas conhecer sua própria história, mas também produzir novos conceitos sobre ela e tomar consciência de seu papel interventivo diante das iniquidades sociais.

Palavras-chave: literaturas africanas, racismo, Brasil, Paulo Freire, educação

\begin{abstract}
This article aims to discuss the study of African Literature in Portuguese Language in schools as an important expression of liberating education, emphasizing reflection on the subject brazilian african descent. We seek to verify to what extent this framework, as an educational resource, helps the students to better know their own history, producing new concepts about it and becoming aware of its intervention role on social inequities.
\end{abstract}

Keywords: African literatures, racism, Brazil, Paulo Freire, education

\footnotetext{
* Doutoranda em Estudos de Literatura pela Universidade Federal Fluminense (UFF).

2 Docente na Universidade Federal Fluminense (UFF).
} 


\section{ntrodução}

A formação de indivíduos conscientes e participativos ocupa posição de destaque quando se discute a educação pensada em/para uma sociedade pluricultural na contemporaneidade. Composta por diferentes classes sociais, etnias, gêneros, faixas etárias, crenças e costumes em interação, a escola é fundamental para a edificação de uma coletividade mais digna, devendo "permitir ao homem chegar a ser sujeito, construir-se como pessoa, transformar o mundo, estabelecer com os outros homens relações de reciprocidade, fazer a cultura e a história" (FREIRE, 1980, p. 39). Sobre ela depositam-se inúmeras expectativas, destacando-se a de que novas gerações possam desenvolver - não apenas em seus discursos, mas também em suas práticas - valores norteados pela legitimação dos direitos e dos deveres de cidadania a todos. Conforme esclarecem Fitoussi e Rosanvallon:

A igualdade é um projeto, um princípio de organização que estrutura o devir de uma sociedade. [...] É um movimento através do qual a sociedade procura libertar, ainda que parcialmente, os indivíduos da sua história para Ihes permitir enfrentar melhor o seu futuro, abrindo-lhes um leque de escolhas que certas circunstâncias do seu passado restringiram em demasia. A ideia de igualdade instaura um combate contra o determinismo, a explicação linear do futuro pelo passado. (FITOUSSI; ROSANVALLON, 1997, p. 64-65)

Refletir acerca da procura por novas formas de convivência em prol da igualdade leva-nos a considerar, inevitavelmente, os obstáculos que comprometem o agenciamento de representações e de interações sociais mais justas. No Brasil, é notório que a concepção da escola como locus igualitário esbarra numa trajetória nacional marcada por complexos níveis de subalternidade: por um lado convivemos com o discurso que nos apresenta como o festivo fruto de várias misturas; por outro, presenciamos cotidianamente a naturalização de inúmeras práticas discriminatórias. 
Orientados por uma perspectiva predominantemente bancária ${ }^{1}$, os discursos escolares implícita ou explicitamente buscam igualar, normatizar e cristalizar sujeitos e saberes, perpetuando trocas díspares entre periferia e centro do sistema. A educação bancária (domesticadora e, em essência, prescritiva), desconsidera diferenças individuais e experiências de vida. Todos os alunos recebem o mesmo "pacote" de conhecimentos, que se pretende neutro e isento de ideologias. Conforme indica Freire:

Quanto mais analisamos as relações educador-educandos, na escola, em qualquer de seus níveis (ou fora dela), parece que mais nos podemos convencer de que estas relações apresentam um cara-ter especial e marcante - o de serem relações fundamentalmente narradoras, dissertadoras. Há a narracão de conteúdos que tendem a petrificar-se ou a fazer-se algo quase morto, sejam valores ou dimensões concretas da realidade. Narração ou dissertação que implica um sujeito o narrador - e objetos pacientes, ouvintes - os educandos Há uma quase enfermidade da narração. A tônica da educação é preponderantemente esta - narrar, sempre narrar. (FREIRE, 1987, P. 57)

Como inegáveis consequências do afastamento entre tais orientações e as realidades do alunado, fracasso, desinteresse, evasão, indisciplina, rebeldia e violência são algumas das problemáticas frequentemente associadas à educação escolarizada no Brasil, ainda "impregnada pela perspectiva do comum, [...] pelo mito do "aqui todos são iguais" (CANDAU, 2000, p. 14). Dessa forma, não basta simplesmente reconhecer a diferença, mas sim pensá-la, discuti-la e integrá-la ao cotidiano escolar: uma vez que as identidades individuais e coletivas são estruturadas, essencialmente, por meio da relação com o outro, assumiremos que uma educação voltada à alteridade abre espaço para um profícuo transcurso de (auto)conhecimento, já que

tudo o que me diz respeito, a começar por meu nome, e que penetra em minha consciência, vem-me do mundo exterior, da boca dos outros [...]. A alteridade indica-me que tomo consciência de mim, originalmente, através dos outros: deles

${ }^{1}$ Utilizamos o termo "educação bancária" de acordo com o que propõe a obra de Paulo Freire $(1980 ; 1987 ; 2004)$. 
recebo a palavra, a forma e o tom que servirão à formação original da representação que terei de mim mesmo (...). Assim como o corpo se forma originalmente dentro do seio (do corpo) materno, a consciência do homem desperta envolta na consciência do outro. (BAKHTIN, 2006, p. 378) (Grifos nossos)

Debruçarmo-nos sobre as demandas de uma educação permeada pelas tensões do mundo globalizado, principalmente em países tomados por grandes desigualdades, leva-nos a questionar a produção da outridade e dos jogos de poder por ela estabelecidos, visto que "a diferença, tal como a identidade, não é um fato [...], é um processo relacional" (SILVA, 2013, p. 101) mediado pela história e pela cultura. As disparidades são muitas, visibilizadas principalmente por movimentos que reivindicam espaço para aqueles que vêm sofrendo, historicamente, uma série de rasuramentos simbólicos, discursivos ou físicos:

O preconceito é uma atitude cultural dirigida a membros de um grupo ou categoria social. Como uma atitude, combina crenças e juízos de valor com predisposições emocionais positivas ou negativas [...] em áreas como inteligência, motivação, caráter moral e habilidades diversas. Essas diferenças são então julgadas segundo os valores culturais das pessoas de status elevado [...]. Finalmente, elementos emocionais como hostilidade, desprezo e temor completam a atitude, criando predisposição [...] para perceber sua própria categoria como socialmente superior. (JOHNSON, 1997, p. 180)

Um dos quadros mais preocupantes quando pensamos os processos discriminatórios no Brasil, sem dúvidas, é o do preconceito contra a população negra. Sabemos que, no país, o termo "raça" afasta-se do sentido biológico e comumente se reveste da ligação entre o fenótipo negro e comportamentos, práticas e estéticas consideradas desqualificadas. Constitui-se, assim, uma perversa construção: segundo dados do Governo Federal, 51\% da população do país são formados por negros e pardos autodeclarados; esses mesmos sujeitos são os que apresentam menores salários, índices de escolaridade e qualidade de vida². Ainda que não se trate de minoria numérica, os negros seguem tratados como

2 Dados da Secretaria de Assuntos Estratégicos. Disponível em: http://www.sae.gov.br/ site/?p=11130. Último acesso em 3 de agosto de 2016. 
minoria sociopolítica e cultural. Nota-se, portanto, que o legado eurocêntrico perpetua o racismo, uma vez que:

[...] pelas suas características e duração histórica, a relação colonial protagonizada por Portugal impregnou de modo muito particular e intenso as configurações de poder social, político e cultural em suas colônias. [...] Esta impregnação colonial do poder, longe de ter terminado com o colonialismo, continuou e continua a reproduzir-se. Assim [...], o fim do colonialismo político não determinou o fim do colonialismo social. (SANTOS, 2006, p. 212) (Grifos nossos)

Ao consideramos tal questão no ambiente escolar, a principal evidência dessa asserção é a invizibilização de África, de suas populações e de suas contribuições para a formação nacional brasileira. Mesmo que o país seja essencialmente híbrido, nossas ligações com o continente foram obliteradas pela coerção das narrativas portuguesas durante séculos, e a associação restrita do negro a estigmas como o exotismo, a miséria e a escravidão deflagra os cenários frequentemente configurados por e para brasileiros:

O modo como a África é vista ou a imagem que dela nos é dada para consumo constitui um exemplo marcante do colonialismo cultural. Apresentada como uma totalidade amorfa, onde a diversidade só é mostrada pela atomização tribal, a África é analisada ainda em termos discriminatórios. [...] No estudo da formação de nossa nacionalidade, a participação dos africanos e de seus descendentes é relegada a uma "contribuição ao folclore, à culinária e ao misticismo". A África permanece para a maioria dos brasileiros reduzida a uma imagem simplificada por quatro 'T's: tribo, tambor, terreiro e... Tarzan. (PEREIRA, 1978, p.16)

Partindo do panorama brevemente esboçado, fica claro que muito deve ser pensado e feito dentro e fora das salas de aula para garantirmos a construção da igualdade. Ao trazermos autores de países aos quais somos ligados pelo idioma e pela história, desejamos promover, a partir da mediação dialógica, uma ressemantização que viabilize representatividades mais justas para o negro brasileiro.

Para pensarmos a situação do afrodescendente e a incipiência da abordagem de África nas escolas, tomamos como ponto de partida uma crucial reflexão de Walter Benjamin sobre o processo de transmissão da cultura. Segundo o crítico: 
Os que num momento dado dominam são os herdeiros de todos os que venceram antes. A empatia com o vencedor beneficia sempre, portanto, esses dominadores. [...] Nunca houve um monumento da cultura que não fosse também um monumento de barbárie. $E$, assim como a cultura não é isenta de barbárie, não o é, tampouco, o processo de transmissão da cultura. (BENJAMIN, 1994, p.225) (Grifos nossos)

Comprometidos com o papel político da educação, sabemos que resgatar a fala do sujeito obliterado é, acima de tudo, um ato de democratização. Em termos legais e acompanhada por medidas como a criação da Secretaria Especial de Políticas de Promoção da Igualdade Racial (SEPPIR), do programa de apoio aos núcleos universitários de estudos afro-brasileiros (UNIAFRO) e da instituição de cotas raciais, foi sancionada pelo ex-presidente Luiz Inácio Lula da Silva, em 9 de janeiro de 2003, a Lei 10.639/03, que institucionaliza o ensino de África nos níveis fundamental e médio, após décadas de reivindicações do movimento negro. A necessidade da criação de uma lei que buscasse garantir o reconhecimento do continente nas salas de aula sinaliza que o Estado brasileiro assume o racismo e as dificuldades que envolvem a construção de identidades afro-brasileiras como problemas estruturais em nosso país. Por instituir uma modificação legislativa, a Lei 10.639/03 torna indispensável o estímulo à pesquisa desses conteúdos dentro e fora da academia: seu advento, além de propiciar a revitalização do diálogo com as matrizes culturais africanas, oficializa a urgência dessa iniciativa.

Pensar a elaboração de planos de aula que contemplem as literaturas africanas implica compreender que a Lei 10.639/03 é um desafio. Para que não se torne letra-morta, é preciso não apenas incluir novos conteúdos, mas reestruturar as metodologias de ensino, os objetivos tácitos e explícitos dos planos de aula e as estratégias de aprendizagem. Mostra-se necessário, em particular, levantar um questionamento capital: se há uma lei que determina o ensino de África, sancionada há mais de dez anos pelo Governo Federal, por que sua presença nas escolas ainda é tão incipiente?

Acreditamos que as dificuldades relativas à implementação da lei fundamentam-se em três aspectos centrais. O primeiro deles diz respeito à falta de investimentos em qualificação adequada por parte dos cursos de ensino normal e superior voltados à formação docente: pautados por uma perspectiva ainda 
beletrista dos conteúdos e das abordagens didáticas, tais instituições acabam por negligenciar o estudo das literaturas africanas, o que compromete a capacitação dos futuros professores e o desenvolvimento de experiências de subsídio.

$\mathrm{O}$ segundo fator liga-se à incipiência de livros, reportagens, vídeos e materiais referentes à temática no espaço escolar. Se pouco é conhecido sobre África em seus tempos passados, geralmente reduzidos a um prisma mítico de "ancestralidade", menos ainda se sabe sobre os contextos pós-coloniais e as atuais demandas de povos que, assim como nós, buscam superar tanto as marcas deixadas pelo modelo colonial quanto as crises propiciadas pelo avanço desenfreado do sistema capitalista.

O terceiro ponto está na falta de ações do próprio Ministério da Educação no tocante ao acompanhamento de planos, currículos, materiais e planejamentos alinhados à lei, o que torna sua aplicação, quando há, consideravelmente superficial. Os efeitos de tais problemas são graves, pois obliteramos a noção de que "a pergunta importante não é 'quais conhecimentos são válidos?', mas sim 'quais conhecimentos são considerados válidos?'” (SILVA, 2013, p. 148) (grifos do autor) quando se pensa a educação brasileira.

Para nós, a proposta de democratização dos currículos e das atuações deve adequar-se às demandas de uma sociedade híbrida; neste sentido, Vera Candau apresenta-nos como possibilidade de intervenção a teoria curricular intercultural, por ser aquela que

se situa em confronto com todas as visões diferencialista que favorecem processos radicais de afirmação de identidades culturais específicas. Rompe com uma visão essencialista das culturas e das identidades culturais. Parte da afirmação de que, nas sociedades em que vivemos, os processos de hibridização cultural são intensos e mobilizadores da construção de identidades abertas, em construção permanente. É consciente dos mecanismos de poder que permeiam as relações culturais. Não desvincula as questões da diferença e da desigualdade presentes na nossa realidade e no plano internacional. (CANDAU, 2005, p. 32)

Uma vez que consolida a prática educacional e que serve como ponte entre sociedade e escola, o currículo é um construto de linguagem - logo, de significação -, tendo claro sentido político ao institucionalizar a maneira como interpretamos a tradição e construímos sentidos. A problematização dos currículos 
nos faz pensar, por exemplo, por que o negro chega à sala de aula não como o humano negro, mas como o objeto escravo, no passado, ou o marginalizado das grandes cidades, no presente, destituído de uma trajetória e de interações sociais diferenciadas. De que formas aparecem, ainda, as contribuições do negro nas áreas de tecnologia, saúde e ciência, campos afastados da imagem folclórica a que normalmente associamos a cultura africana?

Fica claro que não é fácil construir uma identidade negra positiva diante de um "imaginário pedagógico que olha, vê e trata os negros e sua cultura de maneira desigual, representados como rebeldes, maloqueiros, preguiçosos e violentos" (GOMES, 2002, p.5). Não basta falar sobre os afrodescendentes em datas específicas, como o 13 de maio ou o 20 de novembro: a visibilidade desses sujeitos deve fazer parte da rotina escolar, integrando o processo educativo.

Nesse sentido, mostrar aos alunos que a África produz literatura, especialmente em Língua Portuguesa, é fundamental. Elemento frequentemente considerado prisma de uma coletividade, a literatura é lugar fronteiriço, hibridização onde se mesclam teorizações produzidas em diferentes campos disciplinares. Antonio Candido reforça que a literatura é um direito de todo ser humano, pois o torna consciente acerca do respeito e do reconhecimento indispensáveis tanto para nós quanto para o outro:

Entendo por humanização o processo que confirma no homem aqueles traços que reputamos essenciais, como o exercício da reflexão, a aquisição do saber, a boa disposição para com o outro, o afinamento das emoções, a capacidade de penetrar nos problemas da vida, a percepção da complexidade do mundo e dos seres. A literatura desenvolve em nós a quota de humanidade na medida em que nos torna mais compreensivos e abertos para a sociedade. (CANDIDO, 2004, p. 80)

A incursão fornecida pelas escritas de Angola, Cabo Verde, Guiné Bissau, Moçambique e São Tomé e Príncipe permite, dessa forma, que o aluno perceba similaridades, diferenças e marcas identitárias que proporcionam a valorização da afrodescendência. Cabe, portanto, difundirmos a leitura literária de África para mostrar aos estudantes que "quando temos a oportunidade de estudar as literaturas africanas de Língua Portuguesa, estamos buscando as articulações entre ideologias, culturas e práxis artísticas" (ABDALA JÚNIOR, 2007, p.29-30) 
baseadas numa formação intercultural integrada que transporta-nos para o(s) espaço(s) do(s) outro(s).

É válido ressaltar que as independências tardias desses países contribuíram para o desenvolvimento de uma trajetória literária caracterizada por uma vasta escrita de resistência cultural, protesto e combatividade iniciada a partir da década de 40 do século passado (impulsionada, em particular, pela influência da Negritude de Aimé Césaire sobre os jovens da Casa dos Estudantes do Império, associação de universitários colonos que iam estudar na metrópole). Mesmo passada a fase de euforia, diante da ruptura com o sistema colonialista, os escritores contemporâneos (referimo-nos neste ponto às produções pós-80) das nações recém-formadas, escolhidos para a nossa pesquisa, apresentam-nos uma literatura reflexiva, que transita entre o colonial e o pós-colonial para pensar a afirmação da africanidade frente à suposta superioridade europeia ao longo de séculos. Temos, assim, falas que nos mostram simultaneamente o presente e o passado dos países abordados, oferecendo-nos um rico panorama permeado pelo resgate das memórias coletivas.

Tais contradiscursos refutam a historiografia oficial advinda do colonizador, a qual traça o africano como mero subjugado. Somos levados a sujeitos que buscam para si o lugar da enunciação e que apresentam diretamente suas trajetórias, suas demandas e seus anseios:

[...] a relação história / ficção, sendo uma constante nas literaturas que emergem de situações conflituais em processo de automatização (política, cultural, social), é, nas literaturas africanas em Língua Portuguesa, singular. Essa singularidade advém do fato de que pela literatura se vai escrevendo também as memórias coletivas do país. (MATA, 2009, p. 195)

O ensino de literatura constitui-se como processo essencialmente investigativo e dialógico, e é a partir dele que teceremos considerações acerca de como as interações que envolvem educador, educando e texto podem gerar novos olhares sobre a afrodescendência e o sujeito negro. Estamos tratando aqui não somente do diálogo leitor-texto, mas também daqueles que o acompanham: leitor-autor, leitor-personagem, leitor-realidade textual, leitor-realidade social, leitor-contexto de enunciação, leitor-sociedades africanas, leitor sociedade bra- 
sileira, leitor-professor e leitor-leitor são apenas algumas das muitas relações identificáveis nesse verdadeiro exercício polifônico.

Uma vez que Paulo Freire entende a educação como atividade que depende do ato comunicativo para a construção do conhecimento, sua forma de pensar encontra paralelo em Mikhail Bakhtin, cuja obra pauta-se pelo estudo da dialogicidade. Segundo o filósofo russo, "a palavra é fenômeno ideológico por excelência" (...), modo mais puro e sensível de relação, constituição e evolução social" (BAKHTIN-VOLOCHINOV, 1988, p. 36). Dessa forma, nenhum ser humano é determinado previamente, construindo-se à medida que se comunica e que, a partir desse processo, toma consciência do mundo, pois "não foi a educação que fez homens e mulheres educáveis, mas a consciência de sua inconclusão é que gerou sua educabilidade" (FREIRE, 2004, p. 58).

\section{Conclusão}

Paulo Freire mostra-nos que a atuação transformadora é aquela que vai na contramão da perspectiva bancária, a qual trata estudantes como "recipientes", sem trazer à tona discussões ou reflexões sobre as estruturas sociais. Partindo do pressuposto de que a educação não pode ser um enunciado isolado ou monológico, há práxis libertadora - com proposta formativa do ser e de todo seu valor relacional - apenas no ambiente que legitima todos os sujeitos como produtores de sentidos e saberes:

Enquanto na prática "bancária" da educação, antidialógica por essência, por isso não comunicativa, o educador deposita no educando o conteúdo programático da educação, que ele mesmo elabora ou elaboram para ele, na prática libertadora, problematizadora, dialógica por excelência, este conteúdo, que jamais é "depositado", se organiza e se constitui na visão do mundo dos educandos. (FREIRE, 1987, p. 102) (grifos nossos).

Fica claro que a elaboração e a organização dos conteúdos programáticos, bem como das práticas, deve definir-se por meio da interlocução, elemento fulcral para a desconstrução de discursos alienados e alienantes. Pensando o docente como um mediador do processo ensino-aprendizagem, que valoriza a 
vivência e a trajetória dos educandos, levamos em conta a possibilidade de que o alunado, a partir dos temas gerados pelo contato com as literaturas africanas, possa se apropriar dos conhecimentos escolares e extraescolares com visão crítica, convidativa à discussão de temas como igualdade, identidade, cultura e o combate às diversas formas de preconceito:

Nos encontramos imersos nos universos de discursos que nos precederam, internalizamos dos discursos que participamos expressões e compreensões préconstruídas, num processo contínuo de tornar intraindividual o que é interindividual. Mas a cada nova expressão/compreensão pré-construída fazemos corresponder nossas contrapalavras, articulando dialogicamente o que agora se apreende com as mediações próprias do que antes já fora apreendido. (GERALDI, 2010, p. 126) (grifos nossos)

A perspectiva dialógica trabalha, articuladamente, com reflexão e ação. A partir dessa abordagem, torna-se possível confrontar discursos fatalistas e buscar a desautomatização de pensamentos que embasam preconceitos para propiciar mudanças estruturais significativas aos cidadãos brasileiros.

Assim como o ser humano é inacabado, alterando-se permanentemente, inacabada é sua realidade, pressuposto que supera a visão determinista que o reduz a objeto da história. Conscientizamo-nos, desta forma, acerca da diretividade de todos os sujeitos envolvidos na prática educativa e do poder de intervenção que assumimos diante do comprometimento com a desconstrução de iniquidades sociais, especificamente voltando-nos à formulação de contrapalavras que ressignifiquem o lugar do negro em nosso país. 


\section{Referências}

ABDALA JÚNIOR, Benjamin. Literatura, história e política - Literaturas de Língua Portuguesa no século XX. São Paulo: Ateliê Editorial, 2007.

AMÂNCIO, Iris Maria da Costa; GOMES, Nilma Lino; JORGE, Miriam Lúcia dos Santos. Literaturas africanas e afrobrasileiras na prática pedagógica. Belo Horizonte: Autêntica, 2008.

APPIAH, Kwame Anthony. Na casa do meu pai: a África na filosofia da cultura. Tradução de Vera Ribeiro. Rio de Janeiro: Contraponto, 1997.

BAKHTIN, Mikhail. Estética da criação verbal. Tradução de Paulo Bezerra. São Paulo: Martins Fontes, 2006.

BAKHTIN, Mikhail. VOLOCHINOV, Valentin. Marxismo e filosofia da linguagem. Tradução de Paulo Bezerra. São Paulo: Hucitec, 1988.

BHABHA, Homi. O local da cultura. Belo Horizonte: Editora da UFMG, 2001.

BENJAMIN, Walter. Sobre o conceito de história. In: Obras Escolhidas: Magia e técnica, arte e política. Tradução de Sérgio Paulo Rouanet. São Paulo: Brasiliense, 1994.

BRASIL. Lei no 10.639, de 9 de janeiro de 2003. Disponível em: <http://www.planalto. gov.br/ccivil/LEIS/2003/L10.639.htm. - Último acesso: 3 de agosto de 2016.

BRASIL. Parâmetros Curriculares Nacionais de Língua Portuguesa - Terceiro e quarto ciclos do Ensino Fundamental. Disponível em http://portal.mec.gov.br/seb/arquivos/ pdf/livro02.pdf. - Último acesso: 3 de agosto de 2016.

CANDAU, Vera Maria. Reinventar a escola. Petrópolis: Vozes, 2000.

CANDAU, Vera Maria. (Org.). Sociedade multicultural e educação: tensões e desafios. In: Cultura(s) e educação: entre o crítico e o pós-crítico. Rio de Janeiro: DP\&A, 2005.

CANDIDO, Antonio. O direito à literatura. In: Vários Escritos. Rio de Janeiro: Duas cidades, 2004.

FITOUSSI, Jean-Paul.; ROSANVALLON, Pierre. A nova era das desigualdades. Oeiras: Celta Editora, 1997.

FREIRE, Paulo. Pedagogia da autonomia: saberes necessários à prática educativa. São Paulo: Paz e Terra, 2004.

FREIRE, Paulo. Pedagogia do oprimido. São Paulo: Paz e Terra, 1987.

FREIRE, Paulo. Conscientização: teoria e prática da libertação - uma introdução ao pensamento de Paulo Freire. São Paulo: Moraes, 1980.

GADOTTI, Moacir. Diversidade cultural e educação para todos. Rio de Janeiro: Graal, 1992.

GOMES, Nilma Lino. Educação e identidade negra. In: Aletria - revista de estudos de literatura. Alteridades em questão. Belo Horizonte, Faculdade de Letras da UFMG, v.6, n. 9, , p. 38-47, 2002. 
GERALDI, João Wanderley. Ancoragem - estudos bakhtinianos. São Carlos: Pedro \& João Editores, 2010.

HALL, Stuart. "Identidade cultural e diáspora". In: Revista do patrimônio histórico e artístico nacional, no 24: 1996, p. 68-75.

HERNANDEZ, Leila Leite. A África na Sala de Aula. São Paulo: Selo Negro, 2008.

HERNANDEZ, Leila Leite.; LIMA, Heloísa Pires. "A lei 10.639 na sala de aula". In: Revista Caros Amigos. Ano VI, no 71: 2003, p. 32 - 40.

HOBSBAWN, Eric. A invenção das tradições. Tradução de Celina Cardim Cavalcanti. Rio de Janeiro: Paz e Terra, 1984.

JOHNSON, Allan. Dicionário de sociologia: guia prático de linguagem sociológica. Rio de Janeiro: Zahar, 1997.

KI-ZERBO, Joseph. História da África Negra. Mira-Sintra: Europa-América, 1999.

LARANJEIRA, Pires. Ensaios afroliterários. Coimbra: Novo Imbondeiro, 2001.

HERNANDEZ, Leila Leite. Literaturas africanas de expressão portuguesa. Lisboa: Universidade Aberta, 1995.

LEITE, Ana Mafalda. Literaturas africanas e formulações pós-coloniais. Lisboa: Colibri, 2003.

LOPES, Alice Casimiro; MACEDO, Elizabeth. (Orgs.). "Pensamento e política curricular". In: Políticas de currículo em múltiplos contextos. São Paulo: Cortez, 2011.

MATA, Inocência. Literaturas africanas de Língua Portuguesa: redes de cumplicidades, perversas fronteiras. In: Silêncios e falas de uma voz inquieta. Lisboa: Mar além, 2009.

MOSER, Gerald; FERREIRA, Manuel. Bibliografia das literaturas africanas de expressão portuguesa. Lisboa: Lello \& Editores, 1999.

MUNANGA, Kabenguele. (Org.) Estratégias e políticas de combate à discriminação racial. São Paulo: EDUSP, 1996.

NASCIMENTO, Elisa Larkin. O sortilégio da cor: identidade, raça e gênero no Brasil. São Paulo: Selo Negro, 2003.

PADILHA, Laura Cavalcante. Entre voz e letra: o lugar da ancestralidade na ficção angolana do século XX. Rio de Janeiro: EDUFF, 1995.

PEREIRA, José Maria Nunes. Colonialismo, racismo, descolonização. In: Estudos Afroasiáticos. Revista Cândido Mendes, n.2,, p. 47-53, 1978.

SAID, Edward. Cultura e imperialismo. Tradução de Denise Bottmann. São Paulo: Companhia das Letras, 1995.

SANTOS, Boaventura de Sousa. A gramática do tempo: para uma nova cultura política. Porto: Afrontamento, 2006.

SILVA, Tomaz Tadeu. Documentos de identidade: uma introdução às teorias do currículo. Belo Horizonte: Autêntica, 2013. 